Neues aus der Forschung

Redaktion: Josef Gulden

\title{
Melanom (I): Komplettremission bei Mäusen durch Immuntherapie
}

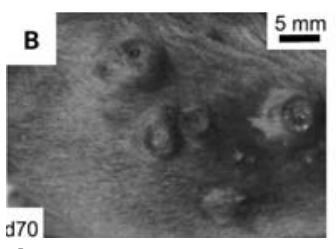

A

Abbildung 1. A. Primäre Melanome bei Mäusen, die etwa von Tag 70 bis Tag 100 nacheinander mit Chemotherapie (C), Lymphozyten (L), einer Virusvakzine (V) und immunstimulierenden Nukleinsäuren (I) behandelt wurden, zeigten im zeitlichen Verlauf eine komplette Remission. B. Ganz ähnliche Remissionen ließen sich bei Lungenmetastasen erzeugen.
Immuntherapien haben bisher auch bei hochimmunogenen Tumoren wie dem Melanom zwar im Tierversuch, nicht aber in der Klinik Erfolg gebracht. Bonner Dermatologen haben nun ein Tiermodell verwendet, in dem genetisch veränderte Mäuse spontan Melanome entwickeln, die auch nach der Transplantation in andere Mäuse ein ähnliches Wachstums- und Metastasierungsverhalten zeigen wie menschliche Tumoren. Von ihnen exprimierte Melanozytenantigene

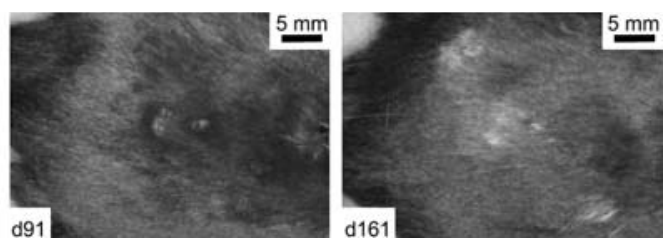

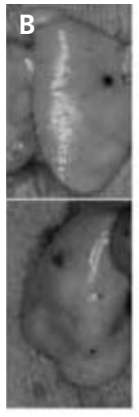

Ctrl d95
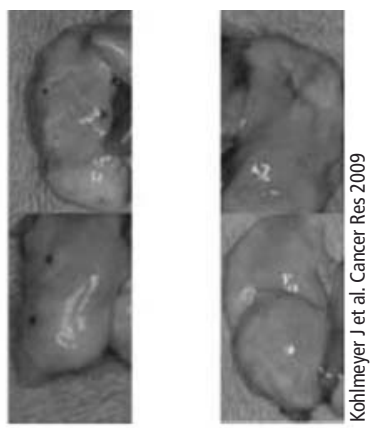

LV d105 C+LV+I d135 werden zwar von antigenspezifischen T-Lymphozyten erkannt, aber in ihrem Wachstumsverhalten nicht nennenswert beeinträchtigt. Diese Tiere wurden deshalb mit einem komplexen, vierteiligen Protokoll behandelt, das neben dem adaptiven auch das angeborene Immunsystem aktiviert.

Nach einer Präkonditionierung mit Cyclophosphamid erhielten sie T-Zellen von Mäusen des gleichen Stammes, die das Melanozytenantigen gp100 erkennen. Außerdem wurden die Tiere mit einem Adenovirus geimpft, das gp100 exprimiert, und schließlich erhielten sie peritumoral ein synthetisches Oligonukleotid injiziert, das als Adjuvans das angeborene Immunsystem stimuliert. Diese Kombinationsbehandlung verursachte eine starke zytotoxische entzündliche Antwort im Tumor und bewirkte eine komplette Remission selbst fortgeschrittener primärer Tumoren in der Haut (Abb. 1a) sowie von Lungenmetastasen (Abb. 1b) bei minimalen Autoimmunreaktionen.

Da dieses Tiermodell klinisch hochrelevant ist, so die Autoren, wäre es vielversprechend, derartige Strategien auch an Patienten zu erproben.

Kohlmeyer J et al. Complete regression of advanced primary and metastatic mouse melanomas following combination chemoimmunotherapy. Cancer Res 2009;69:6265-74.

\section{Melanom (II): Virale RNAs aktivieren die unterdrückte Apoptose}

Melanomzellen sind wie viele andere Tumorzellen resistent gegen Apoptose. Dieser Schutz lässt sich allerdings umgehen, wie Kollegen von den Universitäten Bonn und München zeigen konnten: Sie behandelten Melanomzellen zunächst in vitro mit synthetisch hergestellten viralen RNAMolekülen, die mit Triphosphatresten versehen waren. Diese RNAs werden von Zellen erkannt und lösen normalerweise antivirale Reaktionen wie die Produktion von Interferonen aus. Die Melanomzellen wurden dagegen interferonunabhängig in die mitochondrial initiierte Apoptose getrieben.

Interessanterweise wurde das Apoptoseprogramm auch in gesunden Zellen aktiviert, aber hier konnte das Bcl-xL-Protein den Eintritt in die Apoptose verhindern.

Dies funktioniert auch in vivo: In Mäusen bekämpfte die Gabe der viralen RNA wirksam Lungenmetastasen aus menschlichen Melanomzellen. Bei Verwendung immunkompetenter Mäusestämme ließ sich außerdem eine starke Aktivierung natürlicher Killerzellen zeigen, die ebenfalls die Metastasen angriffen. Da die verwendete Virus-RNA nicht vermehrungsfähig ist, sollte sie auch bei Patienten anwendbar sein.

Besch R et al. Proapoptotic signaling induced by RIG-I and MDA-5 results in type I interferon-independent apoptosis in human melanoma cells. J Clin Invest 2009;119:2399-411. 